\title{
Linfoma Cutâneo Primário de Grandes Células B, Tipo Perna: Relato de Caso com Apresentação Rara
}

\author{
Sousa NA', Buffara MO', Maia RL', Pessoa AS', Cassia FF², Brotas AM' \\ 'Departamento de Dermatologia, Hospital Universitário Pedro Ernesto, Rio de Janeiro, Brasil \\ ${ }^{2}$ Doutora em Dermatologia pela Universidade Federal do Rio de Janeiro, Rio de Janeiro, Brasil
}

RESUMO - Linfomas cutâneos primários são definidos como um grupo heterogéneo de neoplasias malignas linfoproliferativas que acometem a pele, sem evidência de envolvimento extracutâneo no momento do diagnóstico. O subgrupo "linfoma cutâneo primário de grandes células B, tipo perna (PCLBCL, LT)" geralmente acomete um ou ambos membros inferiores, porém 10\% - 15\% dos casos apresentam lesões em outros locais.

Apresenta-se um caso raro de PCLBCL, LT com lesão nodular na região cervical posterior, enfatizando sua apresentação atípica. Considerando o crescimento rápido da lesão e o alto índice proliferativo, é importante conhecer todas as possíveis apresentações clínicas para assim realizar o diagnóstico precoce e instituir o tratamento efetivo.

PALAVRAS-CHAVE - Linfoma Difuso de Grandes Células B/diagnóstico; Linfoma Difuso de Grandes Células B/tratamento; Neoplasias da Pele.

\section{Primary Cutaneous Diffuse Large B Cell Lymphoma Leg Type. An Atypical Presentation}

ABSTRACT - Primary cutaneous lymphomas are defined as a heterogeneous group of malignant lymphoproliferative neoplasms that attack the skin, without extracutaneous involvement at the moment of the diagnosis. The subgroup "primary cutaneous lymphoma of great cells B, leg type (PCLBCL, LT)" generally attacks one or both lower limbs, however in 10\% - $15 \%$ of the cases other areas of the skin may be affected.

We present a rare case of PCLBCL, LT with a nodular lesion located in the cervical region to empathize an atypical presentation. Considering its quick growth and high proliferative rate, it is of great importance to know all its possible clinical presentations for a precocious diagnosis and efficient treatment.

KEYWORDS - Lymphoma, Large B-Cell, Diffuse/diagnosis; Lymphoma, Large B-Cell, Diffuse/therapy; Skin Neoplasms.

\section{INTRODUÇÃO}

Linfomas cutâneos primários são definidos como um grupo heterogéneo de neoplasias malignas linfoproliferativas que acometem a pele, sem manifestações extracutâneas no momento do diagnóstico. ${ }^{1,2}$ Os linfomas cutâneos de células B (CBCL) representam $20 \%$ a $25 \%$ de todos os linfomas cutâneos primários. ${ }^{3} \mathrm{~A}$ classificação proposta pela World Health Organization (WHO) em conjunto com a European Organization for Research and Treatment of Cancer (EORTC) em 2018 divide os CBCL nos seguintes grupos, segundo critérios clínicos, histopatológicos, imunohistoquímicos e moleculares: centrofolicular (PCFCL) e difuso de grandes células $B$, tipo perna (PCLBCL, LT)..$^{1,4,5}$

O grupo PCLBCL, LT, compreende um linfoma raro, muito agressivo e de mau prognóstico, que geralmente acomete um ou ambos os membros inferiores, ${ }^{6,7}$ porém em $10 \%$ - $15 \%$ dos casos apresentam-se com lesões noutros locais da pele. ${ }^{6}$ Apresentamos um caso de PCLBCL, LT com lesão localizada na região cervical posterior. Há poucos relatos na literatura sobre esse tipo de linfoma em localizações
Correspondência: Nathalie Andrade Sousa

Rua Corrêa Dutra, 47 apto 701

Bairro : Flamengo

Rio de Janeiro, RJ

CEP: 22210050 Brasil

E-mail: nathandsousa8@gmail.com

DOI: https://dx.doi.org/10.29021/spdv.78.1.1144
Recebido/Received $2019 / 11 / 25$

(c) Autor (es) (ou seu (s) empregador (es)) e Revista SPDV 2020. Reutilização permitida de acordo com CC BY-NC. Nenhuma reutilização comercial.

(c) Author(s) (or their employer(s)) and SPDV Journal 2020. Re-use permitted under CC BY-NC. No commercial re-use. 


\section{Caso Clínico}

atípicas. ${ }^{2,6}$ Tendo em vista seu rápido crescimento e alto índice proliferativo, é de grande importância o conhecimento de todas as suas possíveis manifestações clínicas para a realização de diagnóstico precoce e tratamento eficaz. ${ }^{8}$

\section{CASO CLÍNICO}

Paciente de 85 anos, sexo feminino, recorreu à consulta por lesão nodular isolada em região cervical posterior, à esquerda, de crescimento rápido, com seis meses de evolução. A lesão era assintomática e a paciente não tinha febre, emagrecimento, sudorese noturna, perda de apetite, prurido ou qualquer outro sintoma. Referia hipertensão arterial, asma e nefrectomia direita por nefrolitíase há 20 anos.

Ao exame físico, apresentava nódulo eritemato-violáceo, medindo $4,5 \times 3 \mathrm{~cm}$, bem delimitado, aderente aos tecidos profundos, infiltrado e de consistência fibroelástica (Fig. 1). Não havia linfonodomegalia, visceromegalia ou outras lesões cutâneas semelhantes. As hipóteses diagnósticas sugeridas foram metástase cutânea, linfoma cutâneo, carcinoma de células de Merkel e melanoma amelanótico.

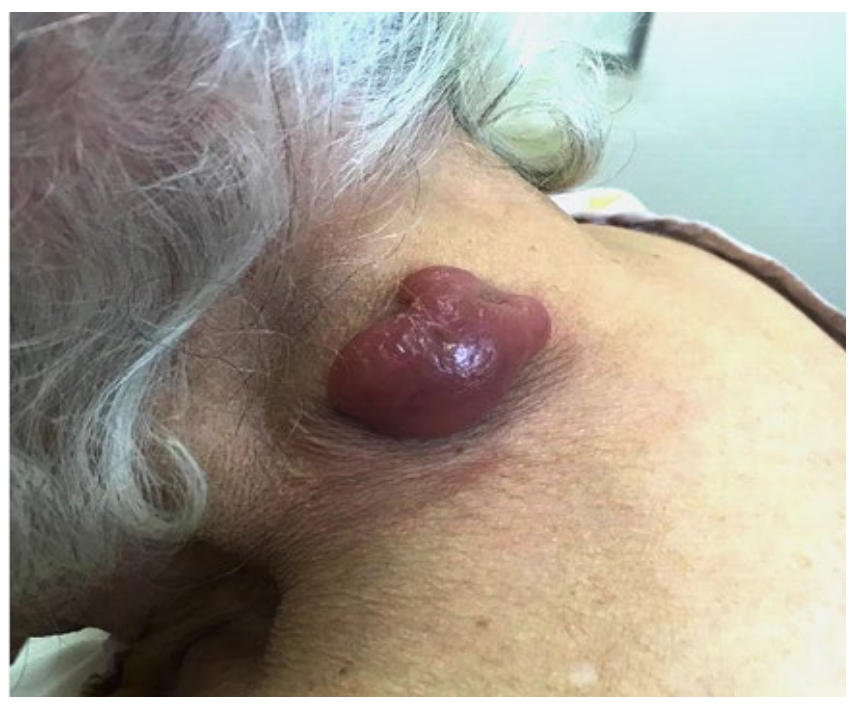

Figura 1 - Lesão tumoral com 6 meses de evolução.

Foi realizada biópsia excisional da lesão (Fig. 2) cujo estudo histopatológico revelou epitélio retificado, zona de Grenz e extenso infiltrado inflamatório, composto na sua maioria por linfócitos atípicos grandes, com figuras de mitose atípicas, sendo sugestivo de linfoma difuso de grandes células (Fig.s 3 e 4). À imunohistoquímica, a lesão foi positiva para CD20, MUM1 e Bcl-2 e negativa para CD3, CD30, CD10 e ciclina D1. O índice proliferativo pelo Ki-67 foi de $80 \%$. Tomografias da região cervical, torácica, abdominal e pélvica mostraram ausência de acometimento extracutâneo. Não foram realizados mielograma, biópsia de medula óssea e estudos de biologia molecular de rearranjo clonal dos genes de imunoglobulinas devido à indisponibilidade desses exames no serviço. Sorologias para os vírus VIH, Epstein Barr (EBV),

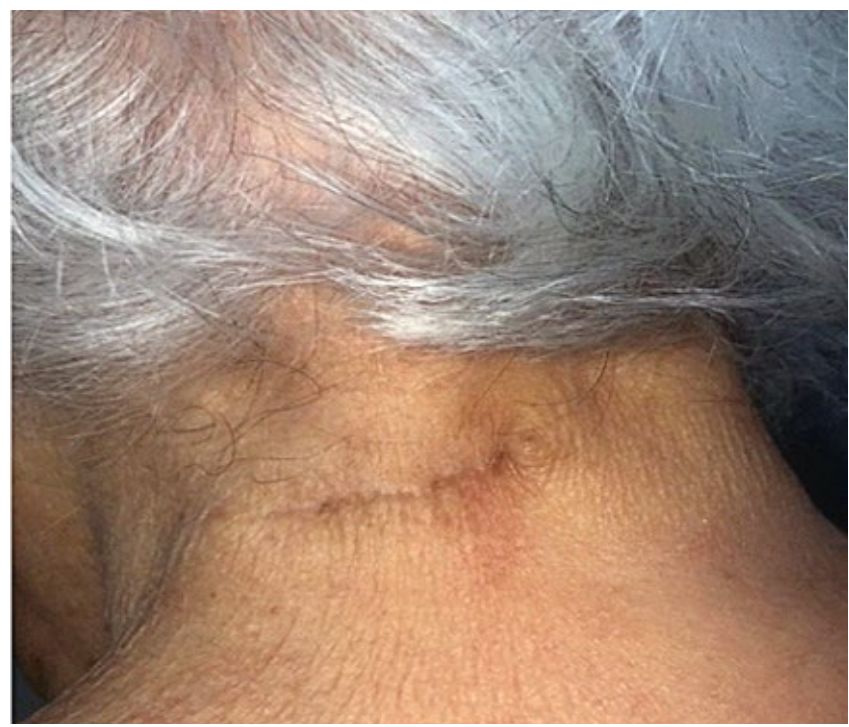

Figura 2 - Cicatriz cirúrgica após exérese da lesão.

citomegalovírus (CMV), hepatite B e C e HTLV foram negativas. Exames laboratoriais revelaram hemograma sem alterações, disfunção renal (creatinina $1,9 \mathrm{mg} / \mathrm{dL}$, função hepática preservada e LDH aumentado (290 UI/L).

Diante dos achados, foi feito o diagnóstico de linfoma cutâneo primário difuso de grandes células $\mathrm{B}$, tipo perna. Baseando-se na classificação TNM para linfomas cutâneos diferentes de micose fungóide ou síndrome de Sézary, o caso foi classificado como $\mathrm{Tl}$ a, pois havia acometimento exclusivamente da pele, com lesão menor que $5 \mathrm{~cm}$, sem acometimento nodal ou metástase extracutânea.

A paciente foi tratada com seis ciclos de quimioterapia, com o esquema mini-CHOP-R (rituximab - $375 \mathrm{mg} / \mathrm{m}^{2}$; ciclofosfamida $400 \mathrm{mg} / \mathrm{m}^{2}$; doxorubicina $25 \mathrm{mg} / \mathrm{m}^{2}$; vincristina 1

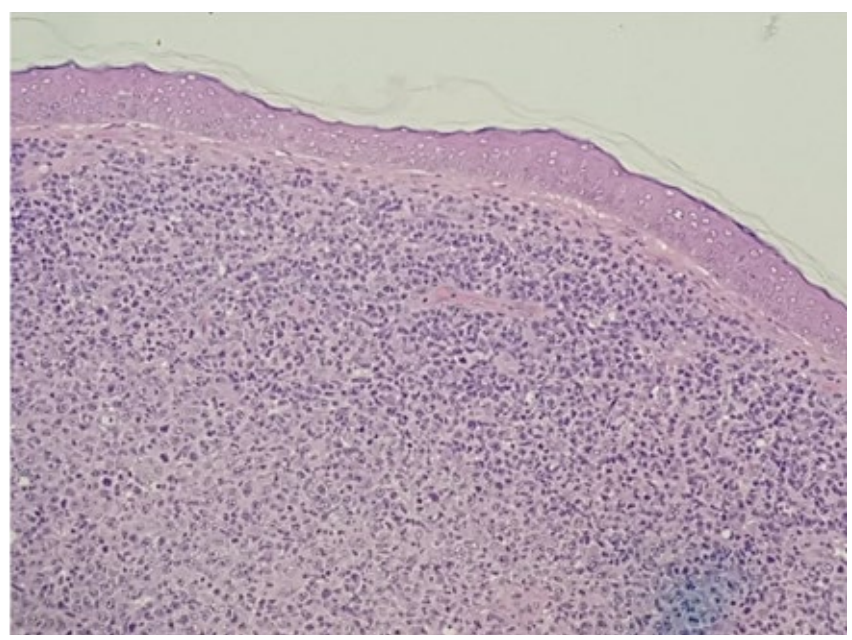

Figura 3 - Cortes histológicos de pele mostrando epitélio retificado, observando-se, na derme, a zona de Grenz e extenso infiltrado inflamatório (H\&E, 10x) 


\section{Caso Clínico}

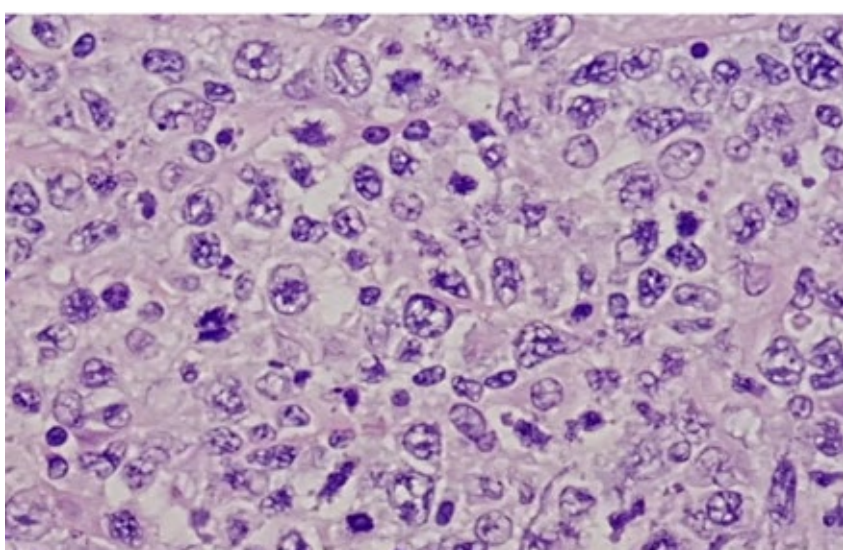

Figura 4 - Cortes histológicos de pele mostrando infiltrado inflamatório compostopor linfócitos atípicos grandes em sua maioria, além de figuras atípicas de mitose. (H\&E, 100x).

mg e prednisona $40 \mathrm{mg} / \mathrm{m}^{2}$ ), em conjunto com a Hematologia. Optou-se por administrar dose reduzida, tendo em vista a idade avançada da paciente e, portanto, maior risco de desenvolver eventos adversos. Ainda assim, a paciente apresentou náusea, vómitos e prostração durante o período em que recebeu quimioterapia. Após seis meses do tratamento, estava assintomática e não foram mais encontradas lesões cutâneas nem linfonodomegalia ao exame físico. A tomografia por emissão de positrões com tomografia computorizada (PET/CT) realizada nessa época também não evidenciou focos de doença linfoproliferativa em atividade.

\section{DISCUSSÃO}

Os locais extranodais mais comumente acometidos por linfomas não-Hodgkin são o trato gastrointestinal, seguido

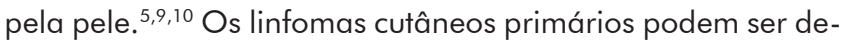
rivados de células $T$, que são os mais comuns $(75 \%$ - $80 \%$ dos casos) ou de células $B(C B C L) .10$ Classicamente, os $\mathrm{CBCL}$ eram divididos em $C B C L$ da zona marginal (PMZL), centro folicular (PCFCL), difuso de grandes células, tipo perna (PCL$B C L, L T)$ e difuso de grandes células, outro (PCLBCLO). No entanto, a nova classificação de 2018, proposta pela WHO-EORTC ${ }^{11,12}$ coloca apenas o PCFCL e o PCLBCL, LT como categorias separadas e agrupa o PMZL juntamente com os linfomas MALT, apesar de muitos autores ainda utilizarem a nomenclatura antiga para se referir a linfomas MALT restritos à pele. ${ }^{10}$

Os pacientes com PCLBCL-LT representam 10\% - 20\% dos casos de $\mathrm{CBCL}$ e $4 \%$ de todos os linfomas cutâneos. ${ }^{13-15}$ Afetam principalmente pacientes do sexo feminino com idade avançada (70-82 anos). ${ }^{13,16}$ Trata-se do tipo mais agressivo de $\mathrm{CBCL}$, com expectativa de sobrevida de $50 \%$ em 5 anos. ${ }^{17}$

O diagnóstico de PCDLBCL-LT é feito por uma combinação de achados clínicos, histopatológicos e de imunohistoquímica. A expressão dos marcadores BCL2, IRF4/MUM1, FOXP1 e BCL6 é característica desse tipo de linfoma e ajuda a diferenciá-lo de outros tipos de tumores, ${ }^{16}$ como o PCFCL, que configura seu principal diagnóstico diferencial. Este apresenta lesões em placas ou tumores envolvendo tronco e crânio, de evolução indolente, em adultos de meia idade. Ao exame histopatológico, é caracterizado por padrão de crescimento folicular, difuso ou misto, constituído por grandes centrócitos derivados de células $B$ do centro germinativo. À imunohistoquímica, é positivo para BCL-6, CD10 de forma variável e negativos para MUM1/IRF-4. A maioria dos casos de PCFCL não expressa de forma significativa BCL2. ${ }^{4}$ Essa característica ajuda a diferenciá-lo do PCDLBCL-LT, o qual apresenta alta expressão desse marcador e prognóstico menos favorável. Ainda, 2/3 dos casos de linfomas tipo perna apresentam expressão concomitante de BCL-2 e c-MYC, o que está associado à menor sobrevida. Além da imunohistoquímica, é fundamental excluir o envolvimento de outros órgãos para concluir o diagnóstico de PCDLBCL-LT, definir a melhor opção terapêutica e informar ao paciente sobre o prognóstico da doença, que será baseado também no perfil de mutações observadas em CD79B, CARD 1 1, mas principalmente nas mutações somáticas do gene MYD88, presentes em até $75 \%$ dos casos. ${ }^{4}$ Existe controvérsia na literatura em relação ao significado dessa mutação. Enquanto um estudo demonstrou ausência de diferença nas características dos pacientes com e sem esta alteração, ${ }^{18}$ outro encontrou associação da mutação no gene MYD88 com menor sobrevida. ${ }^{19}$ Por outro lado, Toberer et al relataram um caso de regressão espontânea PCDLBCL-LT em paciente portador dessa mutação. ${ }^{20}$ Acredita-se que a regressão espontânea do tumor se deva à resposta imunológica a infecção ou a evento traumático. ${ }^{21}$

A maioria dos casos de PCDLBCL-LT acomete os membros inferiores, porém aproximadamente 10\% dos casos apresentam-se em outras regiões da pele. ${ }^{1,5,22}$ Sousa et al relatam um caso de PCDLBCL-LT com lesões ulceradas localizadas nas axilas, em paciente masculino, chamando atenção para a possível apresentação atípica desse tipo de linfoma. ${ }^{2}$ Osada et al descrevem uma lesão na região periorbital, com exame histopatológico e imunohistoquímica compatíveis com PCDLBCL-LT. ${ }^{6}$ Num estudo de análise retrospectiva de 58 pacientes diagnosticados com PCDLBCL-LT, sete $(12,1 \%)$ apresentavam lesões em localizações diferentes dos membros inferiores. ${ }^{17}$ Outro estudo italiano, de coorte retrospectivo, analisou os fatores prognósticos de 467 pacientes com linfoma cutâneo de células B. No subgrupo de pacientes com PCDLBCL-LT, seis dos 51 casos $(11,8 \%)$ tinham lesões localizadas no crânio, tronco ou membro superior. ${ }^{23}$

Existe controvérsia na literatura a respeito dos fatores que influenciam o prognóstico de pacientes com PCDLBCL-LT. Enquanto alguns autores sugerem que o local da lesão está associado à sobrevida do paciente, outros não encontraram diferença significativa entre o desfecho de pacientes com lesões nos membros inferiores e aqueles com lesões em outros locais. ${ }^{1,10}$ Contudo, a presença de múltiplas lesões no momento do diagnóstico parece representar pior prognóstico. ${ }^{24}$ Os doentes com PCDLBCL-LT frequentemente desenvolvem doença extracutânea, sendo os sítios mais acometidos: linfonodos, sistema nervoso central e medula óssea. ${ }^{23}$ 


\section{Caso Clínico}

tratamento dos tipos mais agressivos de linfomas cutâneos de células $B$, principalmente o tipo perna, inclui quimioterapia com o esquema CHOP (ciclofosfamida, doxorrubicina, vincristina e prednisona). A associação ao rituximab, conforme utilizado no caso relatado, parece levar a melhores resultados, com aumento da sobrevida dos pacientes, quando comparado à quimioterapia isolada. Já o rituximab em monoterapia apresenta pior resposta e recorrência mais precoce. ${ }^{25}$

A doxorrubicina lipossomal peguilada é utilizada para tratamento de linfoma cutâneo primário de células T com sucesso e pode ser considerada uma alternativa no tratamento do linfoma cutâneo primário de células $B$, de forma isolada ou associada com rituximab. Estudos demonstratam alta eficácia, baixo nível de toxicidade hematológica e tolerância satisfatória. ${ }^{25}$

A citocina interferon-alfa 2 a modula a progressão do ciclo celular, levando a apoptose e atividade anti tumoral significativa. Também é utilizada, com eficácia, nos linfomas de células $\mathrm{T}$, porém ainda é considerada terapia alternativa em potencial para os $\mathrm{PCBCL}$, pois são poucos os estudos que relatam o seu uso nesses casos. ${ }^{25}$

\section{CONCLUSÃO}

Apresentamos um caso de linfoma cutâneo primário difuso de grandes células $B$, tipo perna, em paciente com perfil epidemiológico característico (sexo feminino, idade avançada), porém de apresentação clínica atípica, pois a lesão localizava-se em região cervical posterior, diferente da maioria dos casos relatados na literatura que se localizam nos membros inferiores. É importante chamar atenção desse tipo de apresentação atípica, a fim de evitar atrasos no diagnóstico e tratamento, que podem influenciar no prognóstico da doença.

Conflitos de interesse: Os autores declaram a inexistência de conflitos de interesse na realização do presente trabalho.

Fontes de financiamento: Não existiram fontes externas de financiamento para a realização deste artigo.

Confidencialidade dos dados: Os autores declaram ter seguido os protocolos da sua instituição acerca da publicação dos dados de doentes.

Consentimento: Consentimento do tutor legal para publicação obtido.

Proveniência e revisão por pares: Não comissionado; revisão externa por pares.

Conflicts of interest: The authors have no conflicts of interest to declare.

Financing support: This work has not received any contribution, grant or scholarship.

Confidentiality of data: The authors declare that they have followed the protocols of their work center on the publication of data from patients.

Patient Consent: Consent for publication was obtained.

Provenance and peer review: Not commissioned; externally peer reviewed
ORCID

Nathalie Sousa

https://orcid.org/0000-0002-3619-201 1

Maria de Oliveira Buffara

https://orcid.org/0000-0002-1583-0125

Allen Pessoa

https://orcid.org/0000-0002-0608-8918

Rafaella Lacerda Maia

https://orcid.org/0000-0001-5214-1022

Flavia Cassia

https://orcid.org/0000-0001-6944-3000

Arles Brotas

https://orcid.org/0000-0001-9830-4763

\section{REFERÊNCIAS}

1. Hope $C B$, Pincus, LB. Primary cutaneous b-cell lymphomas. Clin Lab Med. 2017; 37: 547-74.

2. Sousa AR, Filho EF, Miranda WL, Costa IS, Jucá NB. Primary cutaneous large B-cell lymphoma of atypical presentation - Case report. An Bras Dermatol. 2011; 86: 549-51.

3. Marrero-Alemán G, Montenegro-Dámaso T, Peñate $Y$. Primary cutaneous diffuse large B-cell lymphoma, leg type, with spontaneous regression after biopsy. Am J Dermatopathol. 2017; 39: 785-7. doi: 10.1097/ DAD. 0000000000000874 .

4. Wilcox RA. Cutaneous B-cell lymphomas: 2019 update on diagnosis, risk stratification, and management. Am J Hematol. 2018; 93: 1427-30. doi: 10.1002/ajh.25224.

5. Vermeer $M H$, Willemze R. Recent advances in primary cutaneous B-cell lymphomas. Curr Opin Oncol. 2014; 26: 230-6. doi: 10.1097/CCO.0000000000000060.

6. Osada S, Fujiwara Y, Higashi N, Nakayama K, Hosone $M$, Inokuchi $K$ et al. Primary cutaneous diffuse large B cell lymphoma, leg type, localized in the right periorbital region. J Dermatol. 2018 ;46(4):e130-1. doi: 10.1111/1346-8138.14657.

7. Goyal A, Carter JB, Barnes JA, Duncan LM. Primary Cutaneous Diffuse Large B-Cell Lymphoma, Leg Type. In: Carter J, Goyal A, McDivitt Duncan L, editors. Atlas of Cutaneous Lymphomas. Berlin: Springer; 2015.

8. Patsatsi A, Kyriakou A, Karavasilis V, Panteliadou K, SotiriadisD. Primary cutaneous diffuse large B-cell lymphoma, leg type, with multiple local relapses: case presentation and brief review of literature. Hippokratia. 2013; 17: 174-6.

9. KhatibY, Dande M, Patel RD, Makhija M. Primary cutaneous large B-cell lymphoma of scalp: Case report of a rare variant. Indian J Pathol Microbiol. 2017;60:26871. doi: 10.4103/0377-4929.208414.

10. Pinter-Brown LC. Diagnosis and management of cutaneous B-cell lymphoma. Dermatol Clin. 2015; 33: 83540.

11. Willemze R, Cerroni L, Kempf W, Berti E, Facchetti F, Swerdlow SH, et al. The 2018 update of the WHO-EORTC classification for primary cutaneous lymphomas. 


\section{Caso Clínico}

Blood. 2019;133:1703-14. doi: 10.1182/blood-2018$11-881268$.

12. Swerdlow SH, Campo E, Harris NL, Jaffe ES, Pileri AS, Stein $\mathrm{H}$, et al. WHO classification of Tumors of Haematopoietic and Lymphoid Tissues. 4th ed. Lyon: International Agency for Researchon Cancer; 2017.

13. Willemze R, Jaffe ES, Burg G, Cerroni L, Berti E, Swerdlow $\mathrm{SH}$, et al. WHO-EORTC classification for cutaneous lymphomas. Blood 2005; 105: 3768-85.

14. Sokol L, Naghashpour M, Glass F. Primary cutaneous B cell lymphomas: recent advances in diagnosis and management. Cancer Control. 2012; 19:236-44.

15. Thomas V, Dobson R, Mennel R. Primary cutaneous large B cell lymphoma, leg type. Proc. 2011; 24:350-3.

16. Hristov AC. Primary cutaneous diffuse large B-cell lymphoma, leg type. Arch Pathol Lab Med. 2012; 13:87681.

17. Senff NJ, Hoefnagel JJ, Jansen PM, Vermeer MH, Baarleen JV, Blokx WA, et al. Reclassification of 300 Primary Cutaneous B-Cell Lymphomas According to the New WHO-EORTC Classification for Cutaneous Lymphomas: Comparison With Previous Classifications and Identification of Prognostic Markers. J Clin Oncol. 2007; 25:1581 7.

18. Pham-Ledard A, Cappellen D, Martinez F, Vergier B, BeylotBarry M, Merlio JP. MYD88 somatic mutation is a genetic feature of primary cutaneous diffuse large B-cell lymphoma, leg type. J Invest Dermatol. 2012; 132:211820. doi: 10.1038/jid.2012.102.

19. Pham-Ledard A, Beylot-Barry M, Barbe C, Leduc M,
Petrella T, Vergier B, et al. High frequency and clinical prognostic value of MYD88 L265P mutation in primary cutaneous diffuse large B-cell lymphoma, leg-type. JAMA Dermatol. 2014; 150:1173-9. doi: 10.1001/jamadermatol.2014.821.

20. Toberer F, Mechtersheimer G, Jaschinski H, Enk A, Hakim-Meibodi L, Haenssle HA. Spontaneous regression of primary cutaneous diffuse large B-cell lymphoma, leg type. Acta Derm Venereol. 2018; 98: 608-9. doi: 10.2340/00015555-2921.

21. Jimura N, Fujii K, Baba A, Higashi Y, Kanekura T. Spontaneous regression of a primary cutaneous diffuse large B-cell lymphoma, leg type. J Dermatol. 2017;44: 608-9. doi: 10.1111/1346-8138.13496.

22. Kempf W, Denisjuk N, Kerl K, Cozzio A, Sander C. Primary cutaneous B-cell lymphomas. J Dtsch Dermatol Ges. 2012; 10:12-22. doi: 10.1111/j.1610-0387.2011.07852.x.

23. Zinzani PL, Quaglino P, Pimpinelli N, Berti E, Baliva G, Rupoli $S$, et al. Prognostic factors in primary cutaneous B-cell lymphoma: The Italian Study Group for Cutaneous Lymphomas. J Clin Oncol. 2006; 24:1376-82.

24. Grange F, Beylot-Barry M, Courville P, Maubec E, Bagot $M$, Vergier $B$, et al. Primary cutaneous diffuse large $B$ -cell lymphoma, leg type: clinicopathologic features and prognostic analysis in 60 cases. Arch Dermatol. 2007; 143:1 144-50.

25. Lima M. Cutaneous primary B-cell lymphomas: from diagnosis to treatment. An Bras Dermatol. 2015; 90:687- 706 . 